\title{
INTEGRATED FANP-F-MIGP MODEL FOR SUPPLIER SELECTION IN THE RENEWABLE ENERGY SECTOR
}

\author{
Pinar KAYA SAMUT \\ Faculty of Management, Department of Management, Atilim University, \\ 06836, Incek Golbaşı, Ankara, Turkey \\ E-mails: pinar.samut@atilim.edu.tr;pinar_kaya2003@yahoo.com
}

Received 07 November 2016; accepted 28 April 2017

\begin{abstract}
The available integrated models for choosing efficient suppliers developed so far are mostly specific to companies with mass production capabilities. However, in some sectors involved in project-type manufacturing, the same decision-making criteria cannot be applied and, plus, there is no point in determining the quantity of orders. For instance, in wind power plant projects, a single turbine supplier needs to be selected for each project. This study proposes an integrated FANP-f-MIGP model that ensures the selection of the optimal supplier for each project by applying the model to an energy firm. The criteria specific to the selection of wind power plant turbine suppliers are established, and the criteria weights are obtained by fuzzy analytic network process (FANP). As a result of the analysis, the most important criterion of all is cost. These weights constitute the coefficients of the f-MIGP model's objective function. Under the defined constraints, by minimizing cost and risk and maximizing quality and services of the firm, the selection of an optimal wind turbine supplier from three suppliers for each of three projects is ensured. This study contributes to the literature both by the specific criteria it establishes and its proposed integrated model which allows for the selection of the best supplier in wind turbine and similar project-based productions.
\end{abstract}

Keywords: supplier selection, project-type manufacturing, fuzzy analytic network process, fuzzy mixed integer goal programming, renewable energy sector, wind power plant.

JEL Classification C44, C61, D81, D22, M11, Q49.

\section{Introduction and background}

Selection of the supplier has been a very important issue focused upon by academicians and decision-makers lately. The decision-making process that allows for effective evaluation of suppliers has a very complex structure. This is because the evaluation process includes many aspects that examine the performances of suppliers and the conditions for long-term cooperation with them (Zhang et al. 2012). Nowadays, the relation between manufacturer and supplier is not only about trade relations anymore; it also means partnerships that constitute competitive advantages (Sheth, Sharma 1997). Supplier management is the ability to have a long-term relationship with suppliers and to 
use fewer but trustworthy suppliers. Therefore, selecting the correct supplier requires choosing from a wide array of factors including both qualitative and quantitative elements, rather than simply browsing the price list (Ho et al. 2010). Supplier selection, too, involves a decision-making process with the same requirements.

Techniques such as Multi-Criteria Decision-Making (MCDM), Mathematical Programming (MP) and Artificial Intelligence (AI) have been extensively used in the literature. In some supplier selection problems, one-stage analyses are used, while others prefer twostage integrated methods. Some of the studies that adopt the one-stage analysis method are as follows: AHP (Chan 2003; Kar, Pani 2014; Dweiri et al. 2016 ), FAHP (Mizrak Özfirat et al. 2014; Lo, Sudjatmika 2016), FTOPSIS (Boran et al. 2009; Roshandel et al. 2013; Dowlatshahi et al. 2015), ANP and FANP (Tseng et al. 2009; Kang et al. 2012; Razmi et al. 2009), DEA (Weber, Desai 1996; Braglia, Petroni 2000), MOP (Feng et al. 2011; Arikan 2013), LP (Ng 2008), GP (Ding et al. 2005; Lin, Yeh 2010; Jadidi et al. 2015), f-MIGP and f-MILP (Kumar et al. 2004; Bohner, Minner 2017).

In the two-stage methods within the literature, supplier selection is performed using two or more methods together. As in the present study, other works that have used MCDM in the first stage and MP in the second stage can be summarized as follows: Perçin (2006), in his study where he integrated analytic hierarchy process (AHP) and multi-objective pre-emptive goal programming (PGP) methods, conducted a supplier selection for a company that operates in the automotive sector and determined the order quantity. Çebi and Bayraktar (2003) answered the question as to which suppliers the eight raw materials for a food company should be procured by integrating the lexicographic goal programming (LGP) and AHP methods. Kasirian et al. (2010) found the priorities of suppliers in an application they conducted for an automotive company by using AHP and analytic network process (ANP). In the second stage, they determined two goals, namely maximizing the total value of purchase and minimizing the total cost of purchasing, achieved the goals with PGP, and then compared the results from each method. Ku et al. (2010) integrated the fuzzy analytic hierarchy process and fuzzy goal programming (FAHP-FGP) models for global supplier selection and conducted a study indicating how many products should be purchased from the proper ones among the thousands of suppliers. Similarly, Nikou and Moschuris (2016) combined AHP and GP models to select suppliers for the defense industry. The authors calculated the scores of four suppliers selected for the three products purchased by the Department of Defense with the AHP method and ensured the distribution of the ordered amounts to the suppliers in a manner that will use financial resources optimally with the help of GP. Liao and Kao (2010) integrated the Taguchi loss function, AHP and multi-choice GP methods and presented a theoretical study for supplier selection. After determining the optimal suppliers by AHP, Ghodsypour and O'Brien (1998) and Lin et al. (2011) calculated the optimal quantities to be purchased from each supplier by LP so as to minimize costs. By utilizing the Fuzzy MULTIMOORA technique, Çebi and Otay (2016) assessed suppliers, selected three out of five among them and, later in the second stage, determined the optimal order amount to be assigned to these suppliers using FGP. In the same way, Ayhan and Kilic (2015) first obtained the weights of four criteria for five products us- 
ing F-AHP and, in the second stage by using these weights in the Mixed Integer Linear Programming (MILP) model, distributed the ordered amounts among six suppliers. Jolai et al. (2011) and Damghani et al. (2013) selected appropriate suppliers by using TOPSIS in the first stage and FGP in the second. Huang and $\mathrm{Hu}$ (2013) integrated the FANP-GP and De Novo Programming (DNP) methods in Taiwan automotive sector and implemented a two-stage supplier selection. In the first stage, they determined the optimal order quantity to be purchased from the best supplier using FANP-GP; later, they set the source limitations and capacities by DNP and minimized the purchasing budget. Luangpantao and Chiadamrong (2015) proposed a multi-objective linear supplier selection model that reflects the imprecision and risks in the decision-making process. Illustrating their model, they proposed with an example the criteria and supplier weights using F-TOPSIS in the first stage; next, they tested more than one Fuzzy LP model. Kavitha and Vijayalakshmi (2013) obtained the weights of supplier selection criteria by AHP and sorted the suppliers by TOPSIS. Later, they determined the order amounts by Fuzzy Multi Objective Linear Programming (FMOLP). Gupta et al. (2016) proposed an optimization model integrating the fuzzy multi-objective integer linear programming (FMOILP) and AHP models for supplier selection and order allocation problems and applied the model to an Indian firm in automotive sector, designing and producing auto parts.

Although there is not a similar supplier selection study in the renewable energy sector in which the approach by the present paper is also applied, certain studies could be found where MCDM and MP models are employed for several reasons. Heo et al. (2010), for instance, weighed the required criteria for an effective dissemination program in the renewable energy sector using FAHP. Akash et al. (1999) selected the most optimal one among different electricity production resources using AHP; Chen et al. (2010) selected the most optimal one among a number of solar-wind power generation projects with the help of FAHP; and Lee et al. (2009) decided on the most optimal wind farm project in terms of main criteria, benefits, opportunities, costs and risks with a new AHP-based MCDM. Cristobal (2012) and Chang (2015) implemented GP application in order to determine the optimal plant type and location. In order to find the optimal renewable energy source, Büyükozkan and Güleryüz (2016) used DEMATEL-ANP integrated model and for finding optimal renewable energy project, Yazdani-Chamzini et al. (2013) used the COPRAS-AHP integrated model. Shafiee (2015) determined the most suitable risk mitigation strategy for off-shore wind farms using FANP. In turn, Akbari et al. (2017) suggested the most appropriate facility location for off-shore wind farms using AHP and FANP. In the same field of off-shore wind farms, Fetanat and Khorasaninejad (2015) came up with an integrated F-DEMATEL and F-ELECTRE. While Şengül et al. (2015) addressed the issue of renewable energy supply systems in Turkey using the F-TOPSIS method, Tahri et al. (2015) calculated the weights of the criteria used to determine the location of solar farms using the AHP method. Ghosh et al. (2016) obtained the importance weights for the energy produced from ocean waves as a renewable energy source using AHP, and determined the suitable location with an index established based on the ANN method. 
As summarized above, studies conducted on the supplier selection usually deal with the selection of suppliers in mass production and usually measure the criteria weights in the first stage and determine the order amount to be procured from each supplier in the second. On the other hand, in wind power plant projects, usually there is a need to work with a single turbine supplier and it is not possible to divide the order quantity between suppliers. The selection of wind turbine supplier is a process with an uncertain structure that includes both the qualitative and quantitative data together as in the other sectors. In these projects, it is quite a challenge for administrators to determine the weights of the objective function. Besides, energy firms may implement simultaneous or consecutive projects with high budgets and long life-span. In such a case; in order to minimize the losses that might arise from changing circumstances, prices and possible conflicts, companies have to work with efficient and accurate suppliers.

Due to such reasons, the present paper carries out the selection of an optimal supplier for each wind power plant project using an integrated fuzzy analytic network process and fuzzy mixed integer goal programming (FANP-f-MIGP) model. The first aim of the study is to determine the specific criteria for wind turbine supplier selection and to develop a supplier selection model that uses these criteria as a base. The second aim is to explain how an integrated FANP-f-MIGP model can be used to determine the optimal wind turbine supplier by minimizing the cost and risk of suppliers and maximizing quality and services.

The present study involves two stages. In the first stage, wind turbine supplier selection criteria are determined by FANP and their weights are obtained. ANP method is an extended version of AHP and it is preferred in the analysis of complex systems. It is not possible to measure the qualitative factors completely because of the undetermined structure of decision-makers. Therefore, using fuzzy numbers instead of crisp numbers for the measurement of qualitative factors yields more realistic results. Within this context, using FANP is preferred to calculate the weights of the criteria as well as the sub criteria. The proposed model serves two purposes: the imprecision due to personal judgments are better reflected and, thanks to the established network structure, the interdependencies of these decisions can be expressed.

In the second stage, under the constraints defined and the objective function where the criteria weight acquired by FANP are used, the selection of an optimal wind turbine supplier for each wind power plant project is attained. The f-MIGP model is preferred for the solution of this multi-objective problem. Therefore, by considering the linguistic priorities of the decision-makers, a chance to define an imprecise aspiration level for each aim is provided.

The rest of this paper is organized as follows. In the first section, the procedures of FANP-f-MIGP model suggested for wind turbine supplier selection are introduced, and then FANP and f-MIGP models are mentioned. In the second section, the integrated model is applied to the energy firm. In the first stage of the application, supplier selection criteria are specified, FANP model is structured and criteria weights are calculated. In the second stage, optimal suppliers are selected by establishing the f-MIGP model. The last section contains conclusions and future work. 


\section{Methodology}

\subsection{Proposed procedure}

This article suggests an integrated FANP-f-MIGP model for the selection of wind turbine supplier. The integrated FANP-f-MIGP procedure, which is used in selecting wind turbine supplier, is presented in Figure 1. In this model, FANP is used to find out the relative weights of supplier selection criteria; then, by taking these weights as the parameters of the objective function of f-MIGP model, the optimal supplier is determined for each project.

In the first stage of the proposed integrated model, FANP is used to obtain the weights of the wind turbine supplier selection criteria. The model embodies the five steps listed below:

Step 1: Wind turbine supplier selection criteria of decision maker are identified.

Step 2: The ANP model is structured by its goal, factors and sub-factors determined in the previous step.

Step 3: Pairwise comparison matrices are formed by the decision committee using the scale given in Table 2.

Step 4: The local and global weights of factors and sub-factors are calculated by Chang's extent analysis method (Chang 1996).

Step 5: The weights for main goals (cost, quality, service, risk) are determined in accordance with the obtained weight values.

In the second stage, the suppliers are evaluated by f-MIGP model and the optimal supplier for each wind power plant project of the firm is allocated. This process also includes five steps as follows:

Step 1: Decision variables for each supplier and project are identified.

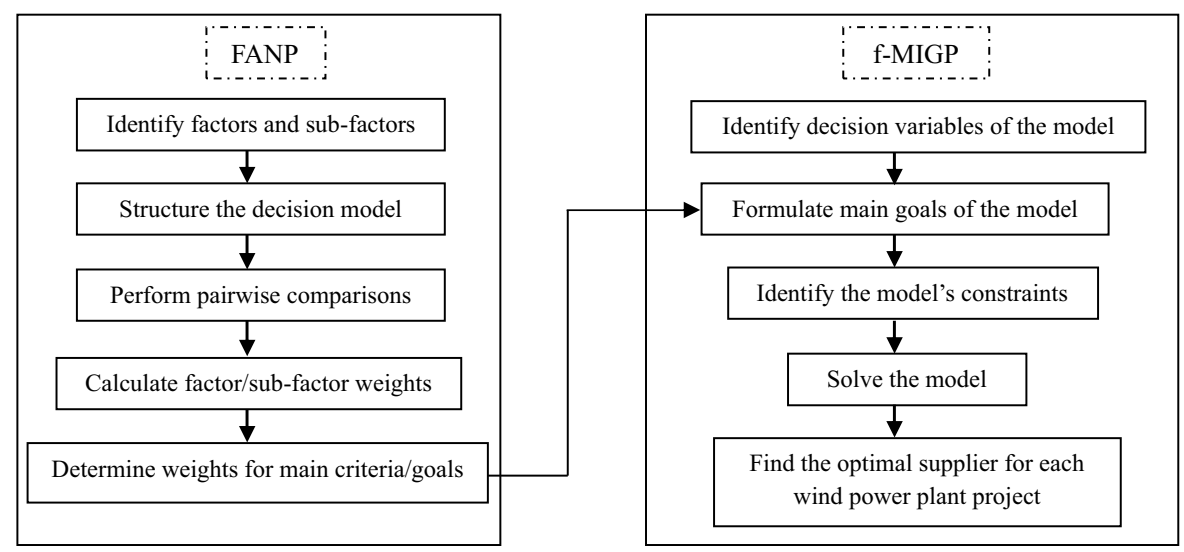

Fig.1. An integrated FANP-f-MIGP procedure for wind turbine supplier selection 
Step 2: By using the obtained weights in the first stage, the main goals of f-MIGP model are formulated. The main goals are cost minimization, quality maximization, service maximization and risk minimization.

Step 3: Turbine supplier selection constraints of the decision maker for wind power plant projects are identified.

Step 4: f-MIGP model is solved which evaluates each possible supplier for each project based on achieving the main goals under determined constraints.

Step 5: The optimal supplier for each wind power plant project is filtered.

\subsection{Fuzzy analytic network process (FANP)}

The Analytic network process (ANP) is a multi-criteria decision-making (MCDM) method which is developed by Saaty (1996). ANP is a generalization of the AHP, which was proposed by Saaty in 1980. The AHP method defines a one-dimensional hierarchical relationship between the criteria, sub criteria and alternatives. However, such a hierarchical structure cannot be applied to many real-life problems due to the interaction between its criteria (Saaty, Takizawa 1986; Saaty 1996). On the other hand, ANP evaluates a multi-dimensional dynamic relationship among the factors with the network structure it devises. The ANP method provides an opportunity for interaction and feedback both within and between the factors. Such feedbacks are more useful in more complex models that may involve uncertainty and risk (Meade, Sarkis 1999). While ANP, unlike AHP, does not require an independence assumption among the criteria, it uses a network structure that reflects all possible dependencies among those criteria, thus enabling ANP to provide more realistic results.

Pairwise comparisons in conventional ANP are inadequate to reflect the actual opinions of the decision-makers because such opinions have uncertainties. Both AHP and ANP techniques use pair-wise comparison of the criteria and sub-criteria in weighing the alternatives. Due to the uncertainty that exists in personal judgments and opinions, it is rather challenging to thoroughly reflect the decision-makers' opinions in these matrices and come up with a clear assessment (Özceylan et al. 2016). If these personal judgments are represented only with a fuzzy number range instead of a crisp number, the model can easily reflect the imprecision underlying the problems. For this purpose, using fuzzy linguistic variables, verbal statements have to be converted into numeric values. Otherwise, the entire decision-making process will be affected and satisfactory outcomes cannot be reached (Shafiee 2015). Therefore, in the decision-making processes of uncertain structures that include several external factors and rely on human judgment, FANP should be used instead of ANP.

Fuzzy logic was first introduced by Zadeh (1965) and is still used in order to define and solve the uncertainty and imprecision inherent in real-life problems. Using fuzzy values in such cases may result in more reliable results with reduced vagueness and 
complexity. The difficulty in obtaining precise and comprehensive determination of perception through crisp numbers results in employing fuzzy numbers and linguistic variables to have a more reliable insight into the way individuals think (Erdoğan Aktan, Kaya Samut 2013).

In this study, by taking into account the interdependence and inner dependence of the criteria and sub-criteria in the network diagram built by FANP, more efficient and realistic solutions are sought with the help of linguistic variables as to the supplier selection problem that includes uncertain characteristics.

In evaluating fuzzy pair-wise comparisons, Chang's extent analysis method is employed in this study. Chang's extent method is validly used in the literature mostly because of its ease of application (Kahraman et al. 2006; Dagdeviren et al. 2008; Razmi et al. 2009; Moalagh, Ravasan 2013).

Let $X=\left\{x_{1}, x_{2}, \ldots, x_{n}\right\}$ be an object set and $G=\left\{g_{1}, g_{2}, \ldots ., g_{m}\right\}$ be a goal set. According to Chang's approach, each object is taken and an extent analysis for each goal, $g_{i}$, is performed, respectively. Thus, $m$ extent analysis values for each object can be obtained with the following symbols:

$$
M_{g i}^{1}, M_{g i}^{2}, \cdots, M_{g i}^{m}, \quad i=1,2, \cdots, n,
$$

where all the $M_{g i}^{1}(j=1,2, \cdots, m)$ are triangular fuzzy numbers (TFNs). The steps of Chang's extent analysis can be given as below:

Step 1: The value of fuzzy synthetic extent with respect to the $i$ th object is defined as:

$$
S_{i}=\sum_{j=1}^{m} M_{g i}^{j} \otimes\left[\sum_{i=1}^{n} \sum_{j=1}^{m} M_{g i}^{j}\right]^{-1}
$$

To obtain $\sum_{j=1}^{m} M_{g i}^{j}$, perform the fuzzy addition operation of $m$ extent analysis values for a particular matrix, such that:

To obtain $\left[\sum_{i=1}^{n} \sum_{j=1}^{m} M_{g i}^{j}\right]^{-1}$, perform the fuzzy additional operation of $M_{g i}^{j}(j=1,2, \cdots, m)$

$$
\sum_{j=1}^{m} M_{g i}^{j}=\left(\sum_{j=1}^{m} l_{j}, \sum_{j=1}^{m} m_{j}, \sum_{j=1}^{m} u_{j}\right)
$$

values, such that:

$$
\left[\sum_{i=1}^{n} \sum_{j=1}^{m} M_{g i}^{j}\right]=\left(\sum_{i=1}^{n} I_{i,} \sum_{i=1}^{n} m_{i}, \sum_{i=1}^{n} u_{i}\right)
$$

Then, compute the inverse of the vector in Equation 4 as

$$
\left[\sum_{i=1}^{n} \sum_{j=1}^{m} M_{g i}^{j}\right]^{-1}=\left(\frac{1}{\sum_{i=1}^{n} u_{i}}, \frac{1}{\sum_{i=1}^{n} m_{i}}, \frac{1}{\sum_{i=1}^{n} l_{i}}\right)
$$


Step 2: The degree of possibility of $M_{2}=\left(l_{2}, m_{2}, u_{2}\right) \geq M_{1}=\left(l_{1}, m_{1}, u_{1}\right)$ is defined as:

$$
V\left(M_{2} \geq M_{1}\right)=\operatorname{hgt}\left(M_{1} \cap M_{2}\right)=\mu_{M_{2}}(d)=f(x)=\left\{\begin{array}{c}
1, \text { if } m_{2} \geq m_{1} \\
0, \text { if } l_{1} \geq u_{2} \\
\frac{l_{1}-u_{2}}{\left(m_{2}-u_{2}\right)-\left(m_{1}-u_{1}\right)}, \text { otherwise }
\end{array},\right.
$$

where $d$ is the ordinate of the highest intersection point $D$ between $\mu_{M_{1}}$ and $\mu_{M_{2}}$, and $\mathrm{h} g t\left(M_{1} \cap M_{2}\right)$ is a separation index for two fuzzy numbers. To compare $M_{1}$ and $M_{2}$, both $V\left(M_{1} \geq M_{2}\right)$ and $V\left(M_{2} \geq M_{1}\right)$ values are needed. The intersection between $M_{1}$ and $M_{2}$ is seen in Figure 2.

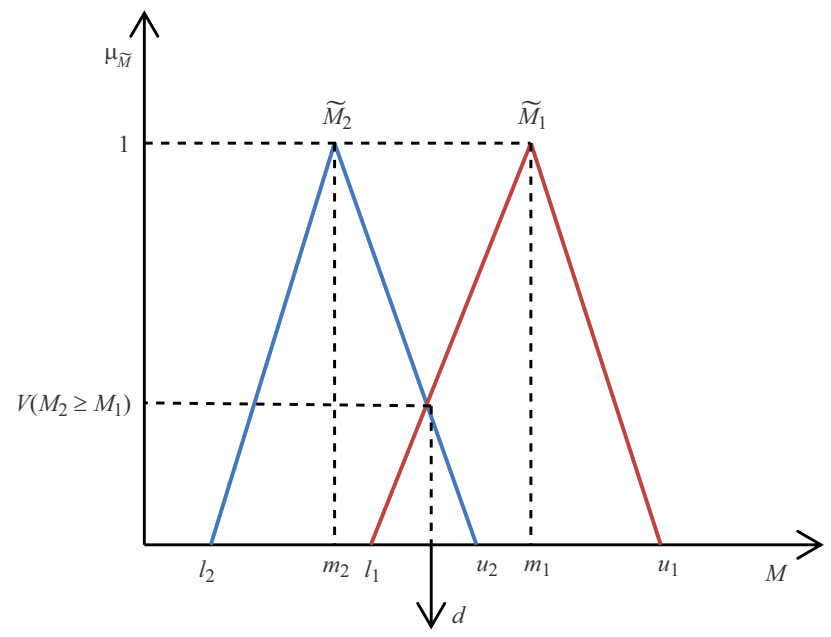

Fig. 2. The intersection between $M_{1}$ and $M_{2}$

Step 3: The degree possibility for a convex fuzzy number to be greater than $k$ convex fuzzy numbers, $M_{i}(i=1,2, \cdots, k)$ can be defined by

$$
\begin{aligned}
& V\left(M \geq M_{1}, M_{2}, \cdots, M_{k}\right)=V\left[\left(M \geq M_{1}\right) \wedge\left(M \geq M_{2}\right) \wedge \cdots \wedge\left(M \geq M_{k}\right)\right], \\
& \quad=\min V\left(M \geq M_{i}\right), i=1,2, \cdots, k .
\end{aligned}
$$

Assume that

$$
d^{\prime}\left(A_{i}\right)=\min V\left(S_{i} \geq S_{k}\right),
$$

for $k=1,2, \cdots, n ; k \neq i$. Then, the weight vector is given by

$$
W^{\prime}=\left(d^{\prime}\left(A_{1}\right), d^{\prime}\left(A_{2}\right), \cdots, d^{\prime}\left(A_{n}\right)\right)^{T},
$$

where $A_{i}(i=1,2, \cdots, k)$ are $n$ elements. 
Step 4: Using normalization, the normalized weight vectors are

$$
W^{\prime}=\left(d\left(A_{1}\right), d\left(A_{2}\right), \cdots, d\left(A_{n}\right)\right)^{T},
$$

where $W$ is a non-fuzzy number.

\subsection{Fuzzy mixed integer goal programming model (f-MIGP)}

The problem of supplier selection is a decision-making problem that includes several goals, constraints and criteria. The traditional GP model, which is a multi-goal decisionmaking approach, was first applied by Charnes and Cooper (1961). GP models minimize the deviation of goal values from the aspiration levels. In this approach, decision-makers need to define a precise aspiration level for each goal; yet, the necessary information for supplier selection process also involves uncertainty. By providing the decision-makers an opportunity to define an imprecise aspiration level, the fuzzy logic helps to reach more appropriate results, especially in large-scale problems. Zimmerman (1978) has defined membership functions for fuzzy linear programming and presented a fuzzy optimization technique for LP problems. Narasimhan (1980), on the other hand, using linear membership functions, suggested an FGP model in which fuzzy goals determine imprecise aspiration levels.

In the present study, multi-goal supplier selection is done with the help of an f-MIGP model, with the mathematical formula as follows:

\section{$\operatorname{Max} \lambda$}

Subject to

$$
\begin{aligned}
& \lambda-\mu_{k}\left(f_{k}\left(x_{i}\right)\right) \leq 0, k=1,2, \cdots, n ; \\
& s_{j}\left(x_{i}\right) \leq a_{j}, j=1,2, \ldots, J \\
& h_{l}\left(x_{i}\right)=b_{l}, \quad l=1,2, \ldots, L \\
& x_{i} \geq 0 \text { and integer, }
\end{aligned}
$$

where $\lambda$ is the extra-continuous variable and $f_{x}(X)$ is the linear function of the $k$ th objective.

In the formulation, $x_{i}$ are $\mathrm{n}$ decision variables, $s_{j}$ are the inequality constraints and $h_{l}$ are the equality constraints. $a_{j}$ and $b_{l}$ are the right hand side constants for inequality and equality relationships, respectively.

A triangular membership function is employed to define fuzzy goals. The fuzzy membership functions of $k$ th objective, $\mu_{k}\left(f_{k}(X)\right)$, are expressed as follows:

$$
\mu_{k}\left(f_{k}(X)\right)=\left\{\begin{array}{cl}
1, & \text { if } f_{k}(X) \geq g_{k}, \\
\frac{\left(f_{k}(X)-l_{k}\right)}{g_{k}-l_{k},} & \text { if } l_{k}<f_{k}(X)<g_{k}, \quad \text { for } f_{k}(X) \succsim g_{k} ; \\
0, & \text { if } f_{k}(X) \leq l_{k}
\end{array}\right.
$$




$$
\mu_{k}\left(f_{k}(X)\right)=\left\{\begin{array}{cl}
1, & \text { if } f_{k}(X) \leq g_{k}, \\
\frac{\left(u_{k}-f_{k}(X)\right)}{u_{k}-g_{k},} & \text { if } g_{k}<f_{k}(X)<u_{k}, \text { for } f_{k}(X) \precsim g_{k} . \\
0, & \text { if } f_{k}(X) \geq u_{k}
\end{array}\right.
$$

where $l_{k}$ and $u_{k}$ are respectively, the lower and upper limits for the $k$ th goal. In the mod-

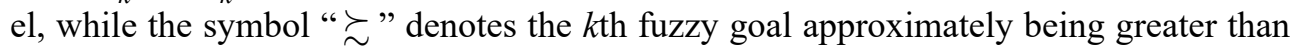
or equal to aspiration level $g_{k}$, the symbol “ $\precsim$ ” indicates being less than or equal to $g_{k}$.

\section{Result}

This case study for the application of an integrated FANP-f-MIGP model is conducted in 2015 in an engineering company in Ankara, Turkey, specialized in renewable energy projects. The study aimed to select an optimal wind turbine supplier for each of the three different wind power plant projects located in different regions and intended to use different types of wind turbines. In wind power plant projects, turbine suppliers not only procure turbines, but they are also liable for the transportation of turbines all the way to their installation and operation. In the study, a network model based on the determined selection criteria of turbine suppliers specific to wind power plants is developed, and the criteria weights are obtained by FANP. Then, an optimal supplier is assigned for each project with the help of the f-MGIP model. All of this process is executed with the decision-making team of the energy department of the company consisting of three individuals. This three-person team, consisting of the manager, the coordinator and the planning engineer, supervise the company's project.

\subsection{FANP model for wind turbine supplier selection}

\section{Wind turbine supplier selection criteria}

To determine the selection criteria for wind turbine suppliers, an extensive list of supplier selection criteria is prepared using the related literature (Liu, Hai 2005; Ku et al. 2010; Tam, Tummala 2001). As stated before, this list was submitted to the decisionmaking team in the energy department which was asked to determine the criteria in order to select the best suppliers. The team agreed on a total of 17 sub-criteria, grouped into four main criteria as: Cost (C1), Quality (C2), Service (C3) and Risk (C4), as in Table 1 .

\section{Structure of FANP model for wind turbine supplier selection}

The FANP model devised to weight the selection criteria of wind turbine supplier is seen in Figure 3. At the first stage of the model, the objective; and at second and third stages the criteria and sub-criteria as in Table 1 are given.

The curves in the second stage indicate the inner-dependencies between the criteria. As a result, the approach allows the analysis of the effects of the models on each other. 
Table 1. Descriptions of criteria and sub-criteria

\begin{tabular}{|c|c|}
\hline \multicolumn{2}{|r|}{ Cost $(C 1)$ : } \\
\hline Product price $(\mathrm{C} 11)$ & Final price of the turbines including installation and warranty \\
\hline Maintenance cost (C12): & Maintenance cost of the turbines upon warranty expirations \\
\hline Spare parts cost (C13): & $\begin{array}{l}\text { Cost of spare parts excluded from scope of warranty and upon its } \\
\text { expiration }\end{array}$ \\
\hline Payment terms (C14): & Customer payments on due dates \\
\hline \multicolumn{2}{|r|}{ Quality (C2): } \\
\hline Quality assurance (C21): & $\begin{array}{l}\text { Quality control team of the suppliers implementing and monitoring } \\
\text { quality issues }\end{array}$ \\
\hline $\begin{array}{l}\text { Problem-solving capability } \\
\text { (C22): }\end{array}$ & Suppliers' ability to solve quality problems detected by customers \\
\hline Product quality (C23): & Turbine production efficiency, material type and design \\
\hline Rejection rate $(\mathrm{C} 24)$ : & Rate of damaged or non-functional components of the turbines \\
\hline \multicolumn{2}{|r|}{ Service $(C 3)$ : } \\
\hline On-time delivery (C31): & Delivery of the components on due dates \\
\hline Technical support (C32): & $\begin{array}{l}\text { On-time action of the turbines technical support team of the } \\
\text { suppliers in case of any breakdowns }\end{array}$ \\
\hline Response to changes (C33): & $\begin{array}{l}\text { Supplier's ability to respond changes depending on customer's } \\
\text { demand, structure of the price, frequency of order and scenario of } \\
\text { the current business }\end{array}$ \\
\hline Warranties (C34): & Length of warranty period and its scope \\
\hline \multicolumn{2}{|r|}{ Risk (C4): } \\
\hline Concept conflict (C41): & $\begin{array}{l}\text { Conflicts that may occur between the customer and the supplier due } \\
\text { to past partnerships }\end{array}$ \\
\hline Geographical location (C42): & $\begin{array}{l}\text { Location of the plant and the possibility of natural calamities } \\
\text { affecting the supply of the components }\end{array}$ \\
\hline Political stability (C43): & Political stability of the supplier's country and its economic policies \\
\hline Financial stability (C44): & Financial status of the supplier based on its history \\
\hline Foreign exchange rate $(\mathrm{C} 45)$ : & $\begin{array}{l}\text { Currency fluctuations during the payment period which may effect } \\
\text { the customer }\end{array}$ \\
\hline
\end{tabular}

\section{Weights of wind turbine supplier selection criteria}

In this section, the weights of the criteria and sub-criteria in the network model are calculated. The pairwise comparison matrices related with the criteria is obtained through a questionnaire distributed to the decision-making team. To obtain the matrices, a linguistic scale for importance is used in Table 2 as defined by Kahraman et al. (2006).

The pairwise comparison matrices are analysed with the help of Chang's extent analysis method, and the local weights of the main criteria and their sub-criteria are calculated (see Table 3-7). 


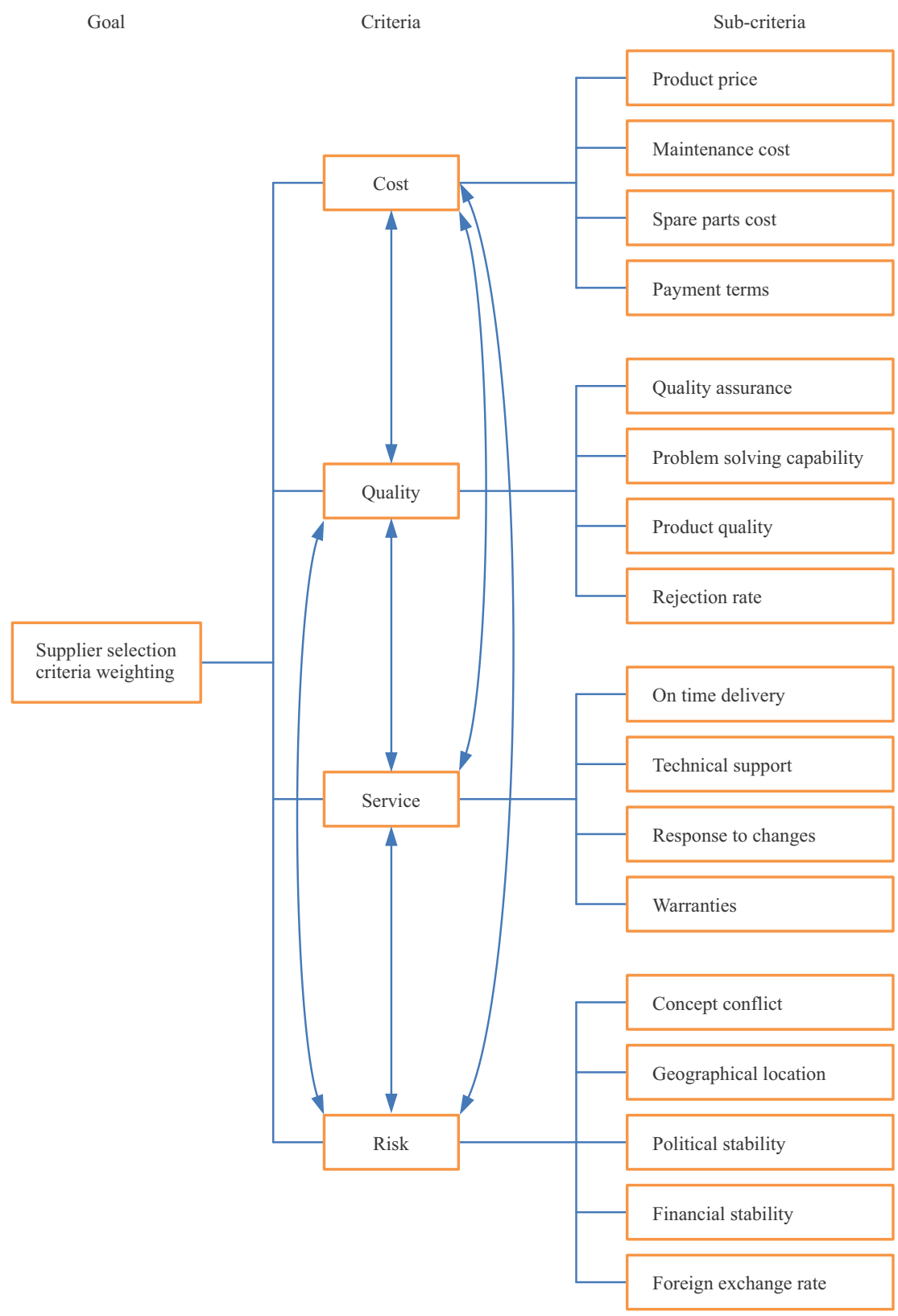

Fig. 3. ANP model to weight supplier selection criteria 
Table 2. Linguistic scale for importance

\begin{tabular}{lcc}
\hline \multicolumn{1}{c}{ Linguistic scale for importance } & $\begin{array}{c}\text { Tringular } \\
\text { fuzzy scale }\end{array}$ & $\begin{array}{c}\text { Tringular reciprocal } \\
\text { fuzzy scale }\end{array}$ \\
\hline Just equal (JE) & $(1,1,1)$ & $(1,1,1)$ \\
\hline Equally important (EI) & $(1 / 2,1,3 / 2)$ & $(2 / 3,1,2)$ \\
\hline Weakly more important (WMI) & $(1,3 / 2,2)$ & $(1 / 2,2 / 3,1)$ \\
\hline Strongly more important (SMI) & $(3 / 2,2,5 / 2)$ & $(2 / 5,1 / 2,2 / 3)$ \\
\hline Very strongly more important (VSMI) & $(2,5 / 2,3)$ & $(1 / 3,2 / 5,1 / 2)$ \\
\hline Absolutely more important (AMI) & $(5 / 2,3,7 / 2)$ & $(2 / 7,1 / 3,2 / 5)$ \\
\hline
\end{tabular}

Table 3. Local weights and pairwise comparison matrix of main criteria

\begin{tabular}{lccccc}
\hline \multicolumn{1}{c}{ Criteria } & C1 & C2 & C3 & C4 & Weights \\
\hline Cost (C1) & JE & WMI & VSMI & SMI & 0.48 \\
\hline Quality (C2) & & JE & SMI & WMI & 0.33 \\
\hline Service (C3) & & & JE & EI & 0.04 \\
\hline Risk (C4) & & & & JE & 0.15 \\
\hline
\end{tabular}

Table 4. Local weights and pairwise comparison matrix of cost (C1) sub-criteria

\begin{tabular}{lccccc}
\hline \multicolumn{1}{c}{ Cost criteria } & C11 & C12 & C13 & C14 & Weights \\
\hline Product price $(\mathrm{C} 11)$ & JE & SMI & VSMI & SMI & 0.57 \\
\hline Maintenance cost (C12) & & JE & EI & & 0.06 \\
\hline Freight cost $(\mathrm{C} 13)$ & & JE & & 0.06 \\
\hline Payment terms $(\mathrm{C} 14)$ & & WMI & SMI & JE & 0.31 \\
\hline
\end{tabular}

Table 5. Local weights and pairwise comparison matrix of quality (C2) sub-criteria

\begin{tabular}{lccccc}
\hline \multicolumn{1}{c}{ Quality criteria } & C21 & C22 & C23 & C24 & Weights \\
\hline Quality assurance (C21) & JE & SMI & & SMI & 0.39 \\
\hline Problem-solving capability (C22) & & JE & & WMI & 0.14 \\
\hline Product quality (C23) & WMI & SMI & JE & SMI & 0.45 \\
\hline Rejection rate (C24) & & & & JE & 0.02 \\
\hline
\end{tabular}

Table 6. Local weights and pairwise comparison matrix of service (C3) sub-criteria

\begin{tabular}{lccccc}
\hline \multicolumn{1}{c}{ Service criteria } & C31 & C32 & C33 & C34 & Weights \\
\hline On-time delivery (C31) & JE & SMI & SMI & WMI & 0.45 \\
\hline Technical support (C32) & & JE & SMI & & 0.23 \\
\hline Response to changes (C33) & & JE & & 0.02 \\
\hline Warranties (C34) & & WMI & WMI & JE & 0.30 \\
\hline
\end{tabular}


Table 7. Local weights and pairwise comparison matrix of risk $(\mathrm{C} 4)$ sub-criteria

\begin{tabular}{lcccccc}
\hline \multicolumn{1}{c}{ Risk criteria } & C41 & C42 & C43 & C44 & C45 & Weights \\
\hline Concept conflict (C41) & JE & & & & EI & 0.04 \\
\hline Geographical location (C42) & WMI & JE & WMI & & & 0.16 \\
\hline Political stability (C43) & SMI & & JE & & EI & 0.17 \\
\hline Financial stability (C44) & SMI & VSMI & SMI & JE & SMI & 0.42 \\
\hline Foreign exchange rate (C45) & & WMI & & & JE & 0.21 \\
\hline
\end{tabular}

In the following step, the degree of dependency among the criteria is determined by analysing the impact of each criterion on every other criterion using pairwise comparisons. In this way, pairwise comparison matrices are formed based on the dependencies represented in the second stage of Figure 3. The computed relative importance weights by their inner dependence matrices are given in Tables 8-11.

Table 8. Inner-dependency matrix of the criteria with respect to "cost"

\begin{tabular}{lcccc}
\hline \multicolumn{1}{c}{ Cost criteria } & Quality criteria & Service criteria & Risk criteria & Weights \\
\hline Quality criteria & JE & WMI & & 0.34 \\
\hline Service criteria & & JE & & 0.1 \\
\hline Risk criteria & WMI & SMI & JE & 0.56 \\
\hline
\end{tabular}

Table 9. Inner-dependency matrix of the criteria with respect to "quality"

\begin{tabular}{lcccc}
\hline \multicolumn{1}{c}{ Quality criteria } & Cost criteria & Service criteria & Risk criteria & Weights \\
\hline Cost criteria & JE & WMI & VSMI & 0.59 \\
\hline Service criteria & & JE & EI & 0.21 \\
\hline Risk criteria & & & JE & 0.2 \\
\hline
\end{tabular}

Table 10. Inner-dependency matrix of the criteria with respect to "service"

\begin{tabular}{lcccc}
\hline \multicolumn{1}{c}{ Service criteria } & Cost criteria & Quality criteria & Risk criteria & Weights \\
\hline Cost criteria & JE & WMI & WMI & 0.45 \\
\hline Quality criteria & & JE & & 0.15 \\
\hline Risk criteria & & SMI & JE & 0.41 \\
\hline
\end{tabular}

Table 11. Inner-dependency matrix of the criteria with respect to "risk"

\begin{tabular}{lcccc}
\hline \multicolumn{1}{c}{ Risk criteria } & Cost criteria & Quality criteria & Service criteria & Weights \\
\hline Cost criteria & JE & SMI & VSMI & 0.76 \\
\hline Quality criteria & & JE & EI & 0.08 \\
\hline Service criteria & & & JE & 0.15 \\
\hline
\end{tabular}


By multiplying the weights acquired from the inner-dependency matrices of the criteria (Table 8-11) with the local weights of the criteria (Table 3), the interdependent weights of the criteria are obtained. The normalized weights of the criteria were found as cost: 0.40, quality: 0.26 , service: 0.09 , and risk: 0.25 . By multiplying the weights of the main criteria with the local weights of the sub-criteria, the global weights of the sub-criteria are obtained (Table 12).

Table 12. Global weights of criteria and sub-criteria

\begin{tabular}{|c|c|c|c|}
\hline Criteria & Weights & Sub-criteria & Weights \\
\hline \multirow[t]{4}{*}{ Cost criteria $(\mathrm{C} 1)$} & 0.40 & Product price $(\mathrm{C} 11)$ & 0.230 \\
\hline & & Maintenance cost (C12) & 0.025 \\
\hline & & Freight cost (C13) & 0.023 \\
\hline & & Payment terms (C14) & 0.126 \\
\hline \multirow[t]{4}{*}{ Quality criteria (C2) } & 0.26 & Quality assurance (C21) & 0.099 \\
\hline & & Problem-solving capability (C22) & 0.037 \\
\hline & & Product quality (C23) & 0.117 \\
\hline & & Rejection rate $(\mathrm{C} 24)$ & 0.004 \\
\hline \multirow[t]{4}{*}{ Service criteria $(\mathrm{C} 3)$} & 0.09 & On-time delivery (C31) & 0.040 \\
\hline & & Technical support (C32) & 0.021 \\
\hline & & Response to changes (C33) & 0.002 \\
\hline & & Warranties (C34) & 0.027 \\
\hline \multirow[t]{5}{*}{ Risk criteria (C4) } & 0.25 & Concept conflict (C41) & 0.009 \\
\hline & & Geographical location (C42) & 0.040 \\
\hline & & Political stability (C43) & 0.043 \\
\hline & & Financial stability (C44) & 0.105 \\
\hline & & Foreign exchange rate $(\mathrm{C} 45)$ & 0.051 \\
\hline
\end{tabular}

According to the results, the most important criterion in the determination of wind turbine supplier is cost, followed by quality and risk. The least weight is at the service criteria. While the two sub-criteria with the maximum weight in cost criterion are "production price" and "payment terms", the criteria with the least weights are "maintenance" and "freight costs". The most important determinant for quality was found to be "product quality"; for risk, "financial stability" and service, this determinant was "on-time delivery".

\subsection{Formulation of f-MIGP for turbine supplier selection in wind power plant projects}

In the second stage of the FANP-f-MIGP integrated model, the suppliers for each of the 3 different projects of the company are determined. The turbine types used in the projects are $3 \mathrm{MW}$ (megawatt) for the first project, $2.3 \mathrm{MW}$ for the second project, and 
3.2 MW for the third project. The suppliers for the projects are selected among 3 firms that provide turbines for the company. In formulating the problem, a single supplier will be worked with in each project, thus requiring integer programming. Therefore, in determining the optimal suppliers for the projects, under certain constraints, an f-MIGP model is established that aims to realize all four objectives.

The decision variables of wind turbine supplier selection model are assigned as 0-1 integer, as stated below.

$$
\text { Decision variable }=x_{i j}=\left\{\begin{array}{ll}
1, & \text { if supplier } i \text { is allocated to project } j \\
0, & \text { otherwise }
\end{array},\right.
$$

where, $i=$ supplier index, $i=1,2,3 ; j=$ project index, $j=1,2,3$.

The objectives of the selection process are to minimize cost and risk and maximize quality and service. The coefficients of the objective function are established with the criteria weights obtained in the first stage with the FANP model.

The lower and upper bound of the goals for the selection model are summarized in Table 13. These bounds indicate the objective limits that the company sets for projects. The minimum and maximum goals are determined for each of the three projects by the decision-making team.

The cost, quality, service and risk factors related to each candidate supplier, S1, S2 and S3, are presented in Table 14.

Table 13. Goals for supplier selection

\begin{tabular}{ccccc}
\hline Criteria \& constraints & \multicolumn{2}{c}{ Goals } & Lower bound & Upper bound \\
\hline G1 & Minimize & Cost & 7750000 & 8850000 \\
\hline G2 & Maximize & Quality & 144 & 156 \\
\hline G3 & Maximize & Service & 156 & 194 \\
\hline G4 & Minimize & Risk & 78 & 108 \\
\hline
\end{tabular}

Table 14. Data set for suppliers with regards to the criteria

\begin{tabular}{ccccc}
\hline Supplier & Cost $(€)$ & Quality (\%) & Service (\%) & Risk (\%) \\
\hline S1 for Project1 & 3100000 & 50 & 60 & 20 \\
\hline S1 for Project 2 & 2800000 & 50 & 60 & 30 \\
\hline S1 for Project 3 & 3250000 & 50 & 60 & 20 \\
\hline S2 for Project 1 & 2750000 & 55 & 50 & 30 \\
\hline S2 for Project 2 & 2500000 & 55 & 50 & 40 \\
\hline S2 for Project 3 & 3000000 & 55 & 50 & 40 \\
\hline S3 for Project 1 & 2500000 & 45 & 70 & 40 \\
\hline S3 for Project 2 & 2250000 & 45 & 70 & 20 \\
\hline S3 for Project 3 & 2850000 & 45 & 70 & 40 \\
\hline
\end{tabular}


The company considers six constraints while selecting suppliers and it will only work with one of the three suppliers in each project. The first three constraints state this condition separately for these three projects. Besides, the company intends to allocate a maximum of two projects to each supplier in order to minimize the risk of possible future conflicts and procurement problems. This condition is defined with the last three constraints.

All the data mentioned above is used to apply the membership functions, and the final weights are calculated accordingly. The f-MIGP structure of the wind turbine supplier selection problem is formulated as follows:

$\operatorname{Max} 0.40 \lambda_{1}+0.26 \lambda_{2}+0.09 \lambda_{3}+0.25 \lambda_{4}$,

$\lambda_{1} \leq \frac{8850000-\left(3100000 x_{11}+2800000 x_{12}+3250000 x_{13}+2750000 x_{21}+2500000 x_{22}+3000000 x_{23}+2500000 x_{31}+2250000 x_{32}+2850000 x_{33}\right)}{1100000} ;$

$\lambda_{2} \leq \frac{\left(50 x_{11}+50 x_{12}+50 x_{13}+55 x_{21}+55 x_{22}+55 x_{23}+45 x_{31}+45 x_{32}+45 x_{33}\right)-144}{12} ;$

$\lambda_{3} \leq \frac{\left(60 x_{11}+60 x_{12}+60 x_{13}+50 x_{21}+50 x_{22}+50 x_{23}+70 x_{31}+70 x_{32}+70 x_{33}\right)-156}{38} ;$

$\lambda_{4} \leq \frac{108-\left(20 x_{11}+30 x_{12}+20 x_{13}+30 x_{21}+40 x_{22}+40 x_{23}+40 x_{31}+20 x_{32}+40 x_{33}\right)}{30} ;$

$x_{11}+x_{21}+x_{31}=1$;

$x_{12}+x_{22}+x_{32}=1$;

$x_{13}+x_{23}+x_{33}=1$;

$x_{11}+x_{12}+x_{13} \leq 2$;

$x_{21}+x_{22}+x_{23} \leq 2$;

$x_{31}+x_{32}+x_{33} \leq 2$,

$\lambda_{j=1,2,3,4} \in[0,1], x_{i j}=0$ or 1.

The optimal solution for this formulation is $x_{11}=0 ; x_{12}=0 ; x_{13}=0 ; x_{21}=1 ; x_{22}=0$; $x_{23}=1 ; x_{31}=0 ; x_{32}=1 ; x_{33}=0 ; \lambda_{1}=0.77 ; \lambda_{2}=0.92 ; \lambda_{3}=0.37$ and $\lambda_{4}=0.60$. According to this result, the company selected supplier 2 for projects 1 and 3 , and supplier 3 for project 2. In other words, the second supplier was assigned to two projects at once, the third supplier was assigned to only one project, and the first supplier was not appointed to any project at all. According to the success results obtained from the four factors, the highest rate belonged to the "quality" factor with $92 \%$ and the lowest one to "service" with $37 \%$. In the optimal solution, the other goals (cost and risk) attained $77 \%$ and $60 \%$ success rates, respectively. With the suppliers it assigned to its projects, the company managed to succeed at most in terms of "quality"; however, with these suppliers, the success in terms of "service" was low. The objective function value is 0.73 as obtained through multiplying the factor success percentages by the factor weights. These values, together with other details, can be viewed in Table 15. In the optimal solution, the degree of achievement of the fuzzy goals $\left(\lambda_{\max }=0.73\right)$ is significantly high. 
In this case, the company appears to have achieved $73 \%$ of the goals it has set. The individual contributions of the goals to this achievement are $0.31,0.24,0.03$ and 0.15 , respectively. While the success rate of the company is high, in order to further this rate, the values pertaining to the cost and risk criteria, which have high objective function coefficients, need to be improved. For this purpose, the $92 \%$ success rate in quality, which is another factor with a high coefficient, has to also be achieved in these criteria. Overall, the company may opt for new suppliers or, alternatively, it may demand the present selected suppliers to focus more on the cost and risk values.

Table 15. Result of sensitivity analysis

\begin{tabular}{cccccc}
\hline \multicolumn{6}{c}{ Sensitivity analysis for the objective function coefficients } \\
\hline Criteria & Solution value & Unit profit & $\begin{array}{c}\text { Total } \\
\text { contribution }\end{array}$ & $\begin{array}{c}\text { Allowable min } \\
\mathrm{c}(\mathrm{j})\end{array}$ & $\begin{array}{c}\text { Allowable } \\
\text { max c(j) }\end{array}$ \\
\hline$\lambda_{1}:$ cost & 0.77 & 0.40 & 0.31 & 0.36 & 0.69 \\
\hline$\lambda_{2}:$ quality & 0.92 & 0.26 & 0.24 & 0.24 & 0.49 \\
\hline$\lambda_{3}:$ service & 0.37 & 0.09 & 0.03 & 0 & 0.12 \\
\hline$\lambda_{4}:$ risk & 0.60 & 0.25 & 0.15 & 0.10 & 0.26 \\
\hline
\end{tabular}

Objective function (max.): 0.73

Sensitivity analysis for the constraint functions

\begin{tabular}{cccccc}
\hline Constraint & Direction & RHS* & Shadow price & $\begin{array}{c}\text { Allowable min } \\
\text { RHS }\end{array}$ & $\begin{array}{c}\text { Allowable } \\
\text { max RHS }\end{array}$ \\
\hline $\mathrm{C} 1$ & $\leq$ & 8850000 & 0 & $-\mathrm{M}$ & $\mathrm{M}$ \\
\hline $\mathrm{C} 2$ & $\geq$ & 144 & -0.0217 & $-\mathrm{M}$ & 155 \\
\hline $\mathrm{C} 3$ & $\geq$ & 156 & -0.0024 & $-\mathrm{M}$ & 170 \\
\hline $\mathrm{C} 4$ & $\leq$ & 108 & 0.0083 & 90 & $\mathrm{M}$ \\
\hline
\end{tabular}

Note: *RHS: right hand-side.

The results of the sensitivity analysis for the model are presented in Table 15, the first section of which presents the sensitivity analysis results for the objective function, and the second section presents the sensitivity analysis results of the constraint equations. The allowable minimum and maximum values in the table indicate the limits that the coefficients can reach without altering the current solution structure. These values allow the company to analyze how much of a variation in the coefficients of the four goals will change the optimal solution structure. Accordingly, with all other parameters remaining constant, the optimal result will not change even if the coefficient of the cost factor of 0.40 decreases to 0.36 or increases to 0.69 . Similarly, this interval is between 0.24 and 0.49 for quality, 0 and 0.12 for service, and 0.10 and 0.26 for risk. Even if the company modifies the weights for these criteria within these intervals, the optimal solution structure will not change.

In the second section of Table 15, the sensitivity analyses are shown for the constraints that the company has determined concerning the cost, quality, service and risk fac- 
tors. In this section, where the variations in the right-hand side (RHS) constants of the constraints are examined, the minimum/maximum RHS values and shadow prices are presented for each constraint equation. Accordingly, even if the company decreases its limit for the risk target of 108 all the way to 90 , the solution structure will not change. However, if it decreases below this limit, another solution composition will emerge. Within these bounds, each time when the company increases the RHS value for the constraint related to the risk factor by one unit - in other words, when it expands the limit - the company's achievement percentage will increase by 0.083 units. On the other hand, when willing to decrease the risk if it tightens the limit, the success percentage will decrease proportionally. The maximum allowed limit values for the quality and service are 155 and 177, respectively. Restricting the limits of these constraints without exceeding them by, for instance, making compromises in the criteria will increase the percentages of the target achievements. Each unit of decrease in the RHS values of the quality and service constraints will, in turn, make for 0.02 and 0.0024 increase in success, respectively. On the other hand, changing the value of the cost constraint, which has a zero shadow price, has no binding effect on the overall success. Obviously, the acceptable limit values are also infinite. The company's increasing or decreasing the cost constraint will not change the total achievement percentage. Within the allowable minimum and maximum limits given earlier, the company may increase the target achievement level by the previously stated rates upon expanding the quality, risk and service constraints. By reviewing its pre-determined lower and upper bounds from this perspective, the company should evaluate whether any alterations need to be made, and assess whether the increase in the success percentage that these compromises will allow are worth the effort.

\section{Conclusions}

Regardless of the sector they operate in, selecting the accurate suppliers and establishing cooperation that provides competitive advantage is very important for companies. Until now, supplier selection has generally been conducted only for mass production systems, and the order quantities are determined by proposed integrated models. Yet, because in the supplier selection process for wind power plants that produce in a project-type manner, there is a necessity to work with a single supplier for each project, it is not naturally possible to divide the order quantity among different suppliers. Also, considering the fact that energy companies under take simultaneous and consecutive projects with high budgets and long life spans, it is vital to determine the optimal supplier with which they can establish long lasting relationships in order to realize the construction and post-construction processes without delay and with the desired quality.

In this study, an integrated FANP-f-MIGP model is suggested and applied to an energy company in order to select the optimal wind turbine supplier for each wind power plant project. With the suggested FANP-f-MIGP model, selection of turbine supplier is performed by considering both qualitative and quantitative factors. In the first stage of the model, by establishing the criteria specific to the selection of wind turbine suppliers, a network model that takes these criteria as the basis is developed and, later, solved using 
the FANP method. In conclusion, the criterion which the company prioritises is cost, followed by risk and service. The weights of the four main criteria obtained constitute the coefficients of the objective function of f-MIGP model in the next stage. Under the defined constraints, the optimal supplier is selected considering cost and risk minimization as well as quality and service maximization. Accordingly, for projects 1 and 3, the second supplier, and for project 2, the third supplier has been selected by the company, whereas the first supplier has not been selected for any project at all. The company's target achievement percentage has been $73 \%$, which is significantly high. Nevertheless, if it wishes to increase this ratio, it would be appropriate for the company to improve its efficiency concerning the cost and risk criteria, which have high objective function coefficients. In general, the company may opt for new suppliers with better performance, or demand improved operations from its current suppliers regarding these criteria. Another way for the company to increase its success rate is to expand the constraints it places on these targets. According to the findings, the cost constraint has no binding effect on the total success rate, although expanding the quality, risk and service constraints increases the success ratio up to a certain level. This allows the company to increase its success level by evaluating the pre-determined lower and upper limits for these constraints.

In the first stage of the suggested model, FANP is used, thereby providing the interaction and feedback both within and between the factors. Identification of the imprecise aspiration level for more than one objective is achieved via f-MIGP. With the FANP-f-MIGP integrated model, a decision mechanism is defined where the linguistic priorities of the decision-makers is considered indispensable for use under uncertain circumstances. The suggested model provides the chance to select the efficient supplier for wind power plant projects and other projects with similar characteristics.

For future studies, it is suggested that applications be increased through development of new criteria and models for other fields within the energy sector. Additionally, new options and settings may be established for different success rates, and the upper and lower target limits and supplier qualities required for the company to achieve these values may be re-defined. In this way, a company can re-determine the alterations it will need to make in terms of constraints, or alternatively seek new suppliers to achieve such success rates.

\section{References}

Akash, B. A.; Mamlook, R.; Mohsen, M. S. 1999. Multi-criteria selection of electric power plants using analytical hierarchy process, Electric Power Systems Research 52(1): 29-35.

https://doi.org/10.1016/S0378-7796(99)00004-8

Akbari, N.; Irawan, C. A.; Jones, D. F.; Menachof, D. 2017. A multi-criteria port suitability assessment for developments in the offshore wind industry, Renewable Energy 102: 118-133. https://doi.org/10.1016/j.renene.2016.10.035

Arikan, F. 2013. A fuzzy solution approach for multi objective supplier selection, Expert Systems with Applications 40(3): 947-952. https://doi.org/10.1016/j.eswa.2012.05.051

Ayhan, M. B.; Kilic, H. S. 2015. A two stage approach for supplier selection problem in multiitem/multi-supplier environment with quantity discounts, Computers \& Industrial Engineering 85: 1-12. https://doi.org/10.1016/j.cie.2015.02.026 
Bohner, C.; Minner, S. 2017. Supplier selection under failure risk, quantity and business volume discounts, Computers \& Industrial Engineering 104: 145-155.

https://doi.org/10.1016/j.cie.2016.11.028

Boran, F. E.; Genç, S.; Kurt, M.; Akay, D. 2009. A multi-criteria intuitionistic fuzzy group decision making for supplier selection with TOPSIS method, Expert Systems with Applications 36(8): 11363-11368. https://doi.org/10.1016/j.eswa.2009.03.039

Braglia, M; Petroni, A. 2000. A quality assurance-oriented methodology for handling trade-offs in supplier selection, International Journal of Physical Distribution and Logistics Management 30(2): 96-111. https://doi.org/10.1108/09600030010318829

Büyüközkan, G; Güleryüz, S. 2016. An integrated DEMATEL-ANP approach for renewable energy resources selection in Turkey, International Journal of Production Economics 182: 435-448. https://doi.org/10.1016/j.ijpe.2016.09.015

Çebi, F.; Bayraktar, D. 2003. An integrated approach for supplier selection, Logistics Information Management 16(6): 395-400. https://doi.org/10.1108/09576050310503376

Çebi, F.; Otay, İ. 2016. A two-stage fuzzy approach for supplier evaluation and order allocation problem with quantity discounts and lead time, Information Sciences 339: 143-157.

https://doi.org/10.1016/j.ins.2015.12.032

Chan, F. T. S. 2003. Interactive selection model for supplier selection process: an analytical hierarchy process approach, International Journal of Production Research 41(15): 3549-3579. https://doi.org/10.1080/0020754031000138358

Chang, C. T. 2015. Multi-choice goal programming model for the optimal location of renewable energy facilities, Renewable and Sustainable Energy Reviews 41: 379-389.

https://doi.org/10.1016/j.rser.2014.08.055

Chang, D. Y. 1996. Applications of the extent analysis method on fuzzy AHP, European Journal of Operational Research 95(3): 649-655.

http://doi:10.1016/0377-2217(95)00300-2

Charnes, A.; Cooper, W. W. 1961. Management models and industrial applications of linear programming. New York: John Wiley and Sons.

Chen, H. H.; Kang, H. Y.; Lee, A. H. I. 2010. Strategic selection of suitable projects for hybrid solar-wind power generation systems, Renewable and Sustainable Energy Reviews 14(1): 413-421. https://doi.org/10.1016/j.rser.2009.08.004

Cristobal, J. R. S. 2012. A goal programming model for the optimal mix and location of renewable energy plants in the north of Spain, Renewable and Sustainable Energy Reviews 16(7): 4461-4464. https://doi.org/10.1016/j.rser.2012.04.039

Dagdeviren, M.; Yuksel, I; Kurt, M. 2008. A fuzzy analytic network process (ANP) model to identify faulty behavior risk (FBR) in work system, Safety Science 46(5): 771-783.

https://doi.org/10.1016/j.ssci.2007.02.002

Damghani, K. K.; Nezhad, S. S.; Tavana, M. 2013. Solving multi-period project selection problems with fuzzy goal programming based on TOPSIS and a fuzzy preference relation, Information Sciences 252: 42-61. https://doi.org/10.1016/j.ins.2013.05.005

Ding, H.; Benyoucef, L.; Xie, X. 2005. A simulation optimization methodology for supplier selection problem, International Journal Computer Integrated Manufacturing 18(2-3): 210-224. https://doi.org/10.1080/0951192052000288161

Dowlatshahi, S.; Karimi-Nasab, M.; Bahrololum, H. 2015. A group decision-making approach for supplier selection in configuration design: a case study, The International Journal of Advanced Manufacturing Technology 81(5): 1139-1154. https://doi:10.1007/s00170-015-7242-8

Dweiri, F.; Kumar, S.; Khan, S. A.; Jain, V. 2016. Designing an integrated AHP based decision support system for supplier selection in automotive industry, Expert Systems with Applications 62: 273-283. https://doi.org/10.1016/j.eswa.2016.06.030 
Erdoğan Aktan, H.; Kaya Samut, P. 2013. Agricultural performance evaluation by integrating fuzzy AHP and VIKOR methods, International Journal Applied Decision Sciences 6(4): 324344. https://doi.org/10.1504/IJADS.2013.056865

Feng, B.; Fan, Z.; Li, Y. 2011. A decision method for supplier selection in multiservice outsourcing, International Journal of Production Economics 132(2): 240-250.

https://doi.org/10.1016/j.ijpe.2011.04.014

Fetanat, A.; Khorasaninejad, E. 2015. A novel hybrid MCDM approach for offshore wind farm site selection: a case study of Iran, Ocean \& Coastal Management 109: 17-28.

https://doi.org/10.1016/j.ocecoaman.2015.02.005

Ghodsypour, S. H.; O’Brien, C. 1998. A decision support system for supplier selection using an integrated analytic hierarchy process and linear programming, International Journal of Production Economics 56-57: 199-212. http://doi:10.1016/S0925-5273(97)00009-1

Ghosh, S.; Chakraborty, T.; Saha, S.; Majumder, M.; Pal, M. 2016. Development of the location suitability index for wave energy production by ANN and MCDM techniques, Renewable and Sustainable Energy Reviews 59: 1017-1028. https://doi.org/10.1016/j.rser.2015.12.275

Gupta, P.; Govindan, K.; Mehlawat, M. K.; Kumar, S. 2016. A weighted possibilistic programming approach for sustainable vendor selection and order allocation in fuzzy environment, The International Journal of Advanced Manufacturing Technology 86(5): 1785-1804.

https://doi.org/10.1007/s00170-015-8315-4

Heo, E.; Kim, J.; Boo, K. J. 2010. Analysis of the assessment factors for renewable energy dissemination program evaluation using fuzzy AHP, Renewable and Sustainable Energy Reviews 14(8): 2214-2220. https://doi.org/10.1016/j.rser.2010.01.020

Ho, W.; Xu, X.; Dey, P. K. 2010. Multi-criteria decision making approaches for supplier evaluation and selection: a literature review, European Journal of Operational Research 202(1): 16-24. https://doi.org/10.1016/j.ejor.2009.05.009

Huang, J. D.; Hu, M. H. 2013. Two-stage solution approach for supplier selection: a case study in a Taiwan automotive industry, International Journal of Computer Integrated Manufacturing 26(3): 237-251. https://doi.org/10.1080/0951192X.2012.685762

Jadidi, O.; Cavalieri, S.; Zolfaghari, S. 2015. An improved multi-choice goal programming approach for supplier selection problems, Applied Mathematical Modelling 39(14): 4213-4222.

https://doi.org/10.1016/j.apm.2014.12.022

Jolai, F.; Yazdian, S. A.; Shahanaghi, K.; Khojasteh, M. A. 2011. Integrating fuzzy TOPSIS and multi-period goal programming for purchasing multiple products from multiple suppliers, Journal of Purchasing \& Supply Management 17(1): 42-53. https://doi.org/10.1016/j.pursup.2010.06.004

Kahraman, C.; Ertay, T.; Buyukozkan, G. 2006. A fuzzy optimization model for QFD planning process using analytic network approach, European Journal of Operational Research 171(2): 390-411. https://doi.org/10.1016/j.ejor.2004.09.016

Kang, H. Y.; Lee, A. H. I.; Yang, C. Y. 2012. A fuzzy ANP model for supplier selection as applied to IC packaging, Journal of Intelligent Manufacturing 23(5): 1477-1488.

https://doi:10.1007/s10845-010-0448-6

Kar, A. K.; Pani, A. K. 2014. Exploring the importance of different supplier selection criteria, Management Research Review 37(1): 89-105. https://doi.org/10.1108/MRR-10-2012-0230

Kasirian, M. N.; Yusuff, R. M.; Ismail, M. Y. 2010. Application of AHP and ANP in supplier selection process-a case in an automotive company, International Journal of Management Science and Engineering Management 5(2): 125-135.

https://doi.org/10.1080/17509653.2010.10671100

Kavitha, C.; Vijayalakshmi, C. 2013. Implementation of fuzzy multi objective linear programming for decision making and planning under uncertainty, Indian Journal of Computer Science and Engineering 4(2): 103-121. 
Ku, C. H.; Chang, C. T.; Ho, H. P. 2010. Global supplier selection using fuzzy analytic hierarchy process and fuzzy goal programming, Quality \& Quantity 44(4): 623-640.

https://doi:10.1007/s11135-009-9223-1

Kumar, M.; Vrat, P.; Shankar, R. 2004. A fuzzy goal programming approach for vendor selection problem in a supply chain, Computers \& Industrial Engineering 46(1): 69-85.

https://doi.org/10.1016/j.cie.2003.09.010

Lee, A. H. I.; Chen, H. H.; Kang, H. Y. 2009. Multi-criteria decision making on strategic selection of wind farms, Renewable Energy 34(1): 120-126. https://doi.org/10.1016/j.renene.2008.04.013 Liao, C. N.; Kao, H. P. 2010. Supplier selection model using Taguchi loss function, analytical hierarchy process and multi-choice goal programming, Computers \& Industrial Engineering 58(4): 571-577. https://doi.org/10.1016/j.cie.2009.12.004

Lin, C. T.; Chen, C. B.; Ting, Y. C. 2011. Supply chain management for a purchasing model: a case study in an electronics firm, Journal of Statistics and Management Systems 14(1): 85-100. https://doi.org/10.1080/09720510.2011.10701544

Lin, Y.; Yeh, C. 2010. Optimal carrier selection based on network reliability criterion for stochastic logistics networks, International Journal of Production Economics 128(2): 510-517.

https://doi.org/10.1016/j.ijpe.2010.07.001

Liu, F. H. F.; Hai, H. L. 2005. The voting analytic hierarchy process method for selecting supplier, International Journal of Production Economics 97(3): 308-317.

https://doi.org/10.1016/j.ijpe.2004.09.005

Lo, S. C.; Sudjatmika, F. V. 2016. Solving multi-criteria supplier segmentation based on the modified FAHP for supply chain management: a case study, Soft Comput 20(12): 4981-4990.

https://doi:10.1007/s00500-015-1787-1

Luangpantao, K.; Chiadamrong, N. 2015. An integrated fuzzy-linear programming approach for a supplier selection problem: a case with multi-sourcing and multi-product scenarios, Suranaree Journal of Science and Technology 22(4): 305-322.

Meade, L. M.; Sarkis, J. 1999. Analyzing organizational project alternatives for agile manufacturing processes: an analytical network approach, International Journal of Production Research 37(2): 241-261. https://doi.org/10.1080/002075499191751

Mızrak Özfirat, P.; Tuna Taşoğlu, G.; Tunçel Memiş, G. 2014. A fuzzy analytic hierarchy process methodology for the supplier selection problem, Journal of Enterprise Information Management 27(3): 292-301. https://doi.org/10.1108/JEIM-12-2013-0094

Moalagh, M.; Ravasan, A. Z. 2013. Developing a practical framework for assessing ERP postimplementation success using fuzzy analytic network process, International Journal of Production Research 51(4): 1236-1257. https://doi.org/10.1080/00207543.2012.698318

Narasimhan, R. 1980. Goal programming in a fuzzy environment, Decision Sciences 11(2): 325-336. https://doi:10.1111/j.1540-5915.1980.tb01142.x

$\mathrm{Ng}$, W. L. 2008. An efficient and simple model for multiple criteria supplier selection problem, European Journal of Operational Research 186(3): 1059-1067.

https://doi.org/10.1016/j.ejor.2007.01.018

Nikou, C.; Moschuris, S. J. 2016. An integrated approach for supplier selection in military critical application items, Journal of Public Procurement 16(1): 83-117.

Özceylan, E.; Kabak, M.; Dağdeviren, M. 2016. A fuzzy-based decision making procedure for machine selection problem, Journal of Intelligent \& Fuzzy Systems 30(3): 1841-1856.

https://doi.org/10.3233/IFS-151895

Perçin, S. 2006. An application of the integrated AHP-PGP model in supplier selection, Measuring Business Excellence 10(4): 34 - 49. https://doi.org/10.1108/13683040610719263 
Razmi, J.; Rafiei, H.; Hashemi, M. 2009. Designing a decision support system to evaluate and select suppliers using fuzzy analytic network process, Computers \& Industrial Engineering 57(4): 1282-1290. https://doi.org/10.1016/j.cie.2009.06.008

Roshandel, J.; Miri-Nargesi, S. S.; Hatami-Shirkouhi, L. 2013. Evaluating and selecting the supplier in detergent production industry using hierarchical fuzzy TOPSIS, Applied Mathematical Modelling 37(24): 10170-10181. https://doi.org/10.1016/j.apm.2013.05.043

Saaty, T. L. 1980. The analytic hierarchy process. New York: McGraw-Hill.

Saaty, T. L.; Takizawa, M. 1986. Dependence and independence: from linear hierarchies to nonlinear networks, European Journal of Operational Research 26(2): 229-237.

http://doi:10.1016/0377-2217(86)90184-0

Saaty, T. L. 1996. Decision making with dependence and feedback: the analytic network process. Pittsburgh: RWS Publications.

Shafiee, M. 2015. A fuzzy analytic network process model to mitigate the risks associated with offshore wind farms, Expert Systems with Applications 42(4): 2143-2152.

https://doi.org/10.1016/j.eswa.2014.10.019

Sheth, J. N.; Sharma, A. 1997. Supplier relationships: emerging issues and challenges, Industrial Marketing Management 26(2): 91-100. http://doi:10.1016/S0019-8501(96)00153-8

Şengül, Ü.; Eren, M.; Shiraz, S. E.; Gezder, V., Şengül, A. B. 2015. Fuzzy TOPSIS method for ranking renewable energy supply systems in Turkey, Renewable Energy 75: 617-625.

https://doi.org/10.1016/j.renene.2014.10.045

Tahri, M.; Hakdaoui, M.; Maanan, M. 2015. The evaluation of solar farm locations applying geographic information system and multi-criteria decision making methods: case study in southern Morocco, Renewable and Sustainable Energy Reviews 51: 1354-1362.

https://doi.org/10.1016/j.rser.2015.07.054

Tam, M. C. Y.; Tummala, V. M. R. 2001. An application of the AHP in vendor selection of a telecommunications system, Omega 29(2): 171-182. https://doi.org/10.1016/S0305-0483(00)00039-6

Tseng, M.; Chiang, J. H.; Lan, L. W. 2009. Selection of optimal supplier in supply chain management strategy with analytic network process and choquet integral, Computers and Industrial Engineering 57(1): 330-340. https://doi.org/10.1016/j.cie.2008.12.001

Weber, C. A.; Desai, A. 1996. Determination of paths to vendor market efficiency using parallel coordinates representation: a negotiation tool for buyers, European Journal of Operational Research 90(1): 142-55. http://doi:10.1016/0377-2217(94)00336-X

Yazdani-Chamzini, A.; Fouladgar, M. M.; Zavadskas, E. K.; Moini, S. H. H. 2013. Selecting the optimal renewable energy using multi criteria decision making, Journal of Business Economics and Management 14(5): 957-978. https://doi.org/10.3846/16111699.2013.766257

Zadeh, L. A. 1965. Fuzzy sets, Information and Control 8(3): 338-353.

http://doi:10.1016/S0019-9958(65)90241-X

Zhang, X.; Lee, C. K. M.; Chen, S. 2012. Supplier evaluation and selection: a hybrid model based on DEAHP and ABC, International Journal of Production Research 50(7): 1877-1889. https://doi.org/10.1080/00207543.2011.560908

Zimmerman, H. J. 1978. Fuzzy programming and linear programming with several objective functions, Fuzzy Sets and Systems 1(1): 45-55. http://doi:10.1016/0165-0114(78)90031-3

Pinar KAYA SAMUT, PhD, is an Assistant Professor of Quantitative Methods at Atılım University, Turkey. Her research interests include fuzzy logic, uncertainty, Multi Criteria Decision Making Techniques, mathematical programming, project management, total factor productivity. Her publications have appeared in such journals as Social Indicators Research, Journal of Intellectual Disability Research, International Journal of Applied Decision Sciences. 